\title{
From Usability to Pleasure: A Case Study of Difference in Users' Preference
}

\author{
Wei Bi ${ }^{1,2}$, Yanru Lyu ${ }^{3}$, Jing Cao4, Rungtai Lin ${ }^{4}$ \\ ${ }^{1}$ School of Art and Design, Guangdong University of Finance and Economics, Guangzhou, China \\ ${ }^{2}$ Southern Publishing and Media Company Limited, Post-Doctoral Research Station Guangzhou, China \\ ${ }^{3}$ Department of Digital Media Art, Beijing Technology and Business University, Beijing, China \\ ${ }^{4}$ Graduate School of Creative Industry Design, National Taiwan University of Arts, Chinese Taipei \\ Email: ${ }^{\star}$ rtlin@mail.ntua.edu.tw
}

How to cite this paper: $\mathrm{Bi}, \mathrm{W} ., \mathrm{Lyu}, \mathrm{Y} . \mathrm{R}$., Cao, J. and Lin, R.T. (2021) From Usability to Pleasure: A Case Study of Difference in Users' Preference. Engineering, 13, 448-462. https://doi.org/10.4236/eng.2021.138032

Received: July 21, 2021

Accepted: August 16, 2021

Published: August 19, 2021

Copyright (c) 2021 by author(s) and Scientific Research Publishing Inc. This work is licensed under the Creative Commons Attribution International License (CC BY 4.0).

http://creativecommons.org/licenses/by/4.0/ (c) (i) Open Access

\begin{abstract}
For past decades, research of designing "pleasure" into products in the academic community has produced a multitude of evaluation models and frameworks. These models address the critical issues of pleasurable product design leading to emotional design. This study is intended to explore the change from the need of "usability" for the product design to the need of "pleasure" for the user experience. The questionnaires were used to obtain data from 343 subjects. The four keyboard designs were adopted in the experiment to study the difference and the change from "usability" to "pleasure" of users" preference. The results show that the need for pleasure is higher than usability, as well as attractive things also transmit the feel of work better. Besides, preference is related to gender, age, major, and educational background. Results presented herein provide designers with a valuable reference for examining the way how to design "pleasure" into product and the interactive experience of users in the design process.
\end{abstract}

\section{Keywords}

Usability, Pleasure, Product Design, Cognitive Ergonomics, Preference

\section{Introduction}

Pleasure is a feeling driven by a positive emotional experience, which is also a kind of user requirement that should be fulfilled in product design. The Oxford English Dictionary defines "Pleasure" as the condition or sensation induced by the experience or anticipation of what is felt to be good or desirable; a feeling of happy satisfaction or enjoyment; delight, gratification. During the period of industrial manufacturing, the emphasis on mass production caused disregard for the indi- 
vidual's preferences and feelings. However, designers have become aware of the importance of creating strong emotional experiences intertwined with new tangible products for the past decade [1]. A person's attitude to artwork and design is not based on logic but on experiential factors which can create and maintain longlasting emotions [2] [3]. Emotion can modify higher-level activities since emotions influence decision-making, affect attention, memory, and so on [4] [5]. Consequently, more and more designers challenge to manipulate the emotional impact of their designs, as positive emotions in products add extra value to the product and further benefit users [6] [7]. There is an increasing interest in understanding and investigating the aspects of products that give people an affective experience [8] [9] [10] [11].

Through many examples, Norman proved that emotions are central for a person to evaluate products [11]. Several emotion-driven approaches have been proposed, which mainly can be identified into two perspectives. The first focuses on the design and evaluation of aesthetic pleasure [8] [9] [12], as well as the latter considers fluent interactions as the critical factor for positive emotion [13] [14] [15]. Desmet and Hekkert [16] conceived a framework of product experience consisting of aesthetic experience, experience of meaning, and emotional experience. Although pleasure seems to behave erratically at one moment, a growing number of researchers believe that designers can develop products to elicit pleasure as the conditions that underlie and trigger it are universal [17]. Based on the model of four pleasures proposed by Tiger [18], physical, social, psychological, and ideological, Jordan [19] used some examples to demonstrate how the four types of pleasure might be relevant in the context of products. Moreover, he argued that the four pleasures are a tool that can help make the design process consider the full spectrum of pleasures that a product can bring.

New research has shown that attractive things really do work better. Norman explained why they must also be attractive, pleasure, and fun [11]. The affective responses to product appearance can be a determinant of product attachment and also influence purchase decisions [20] [21]. With the increase of consumers shop online in the Internet era, can products still enhance preferences by providing pleasure? It is worth discussing the pleasures of products from the perspective of perceiver preference.

This study sought to explore the pleasures of products from users' preferences. Based on the four pleasures served by Jordan [19], an experiment is designed to analyze pleasure in user's preferences facing common-use technological products. Furthermore, the key factors that impacted the preference were discussed. The contribution might be used as assistance to design "pleasure" into products and enhance the interactive experience of users in the design process.

\section{Research Framework}

According to the International Organization for Standardization (ISO) 9241-11, usability is the extent to which specific users can use a system, product, or service 
can achieve specific objectives with effectiveness, efficiency, and satisfaction in a specific context of use. The definition emphasized the measurable facets of usability that are assessed concerning the context of use. Guided by sets of usability principles [22] [23], usability-based methods focus on user characteristics such as behavior, cognition, and attitude to improve the three factors of usability mentioned above.

Nevertheless, usability-based approaches are inherently limited as they tend to look at products as a tool for the user to complete a task. Products are living objects having relationships with people. Users experienced displeasure most with poor usability, whereas they experienced pleasure most with good features [24]. Jordan [25] advocated that creating pleasurable products should begin with understanding and empathizing with users and refer to their concern, want, taste, usage scenarios, and then using pleasure analysis instead of usability to define a product specification. He also proposed a framework of four pleasures and explained them from the perspective of products, as shown in Table 1. Hekkert [8] advanced general principles of aesthetic pleasure: 1) maximum effect for minimum means, 2) unity in variety, 3) most advanced, yet acceptable, and 4) optimal match. Norman [11] found the importance of balance among the three levels: visceral, behavioral, and reflective designs.

Based on the previous studies, there are apparent differences between usability-based design and pleasure-based design both in goals and approaches. The main purpose of this paper is to explore whether there is a change from the need for "usability" for the product design to the need of "pleasure" for the user experience. Figure 1 shows the research framework, which focuses on the difference of perception in four types of pleasure between the usability-based design and pleasure-based design. As a common-use technology product, keyboards were designed as stimuli with usability or pleasure according to their corresponding methods and goals. Through the preference experiment, this study attempts to find out the different reactions of the subjects with different gender, ages, majors and educational

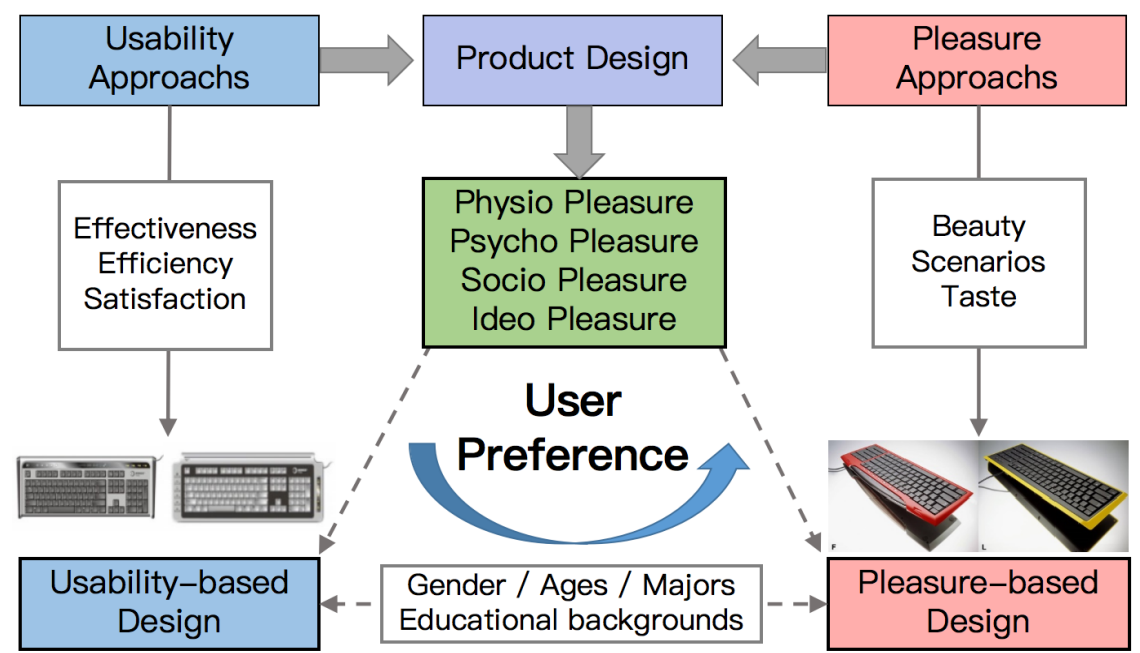

Figure 1. The research framework. 
Table 1. Pleasure-based approach by Jordan [19].

\begin{tabular}{cl}
\hline Types of Pleasure & \multicolumn{1}{c}{ Explanation in Perspective of Products } \\
\hline Physio Pleasure & $\begin{array}{l}\text { The pleasure directly derived from the multiple body sense organs during } \\
\text { holding, touching, and operating the product. }\end{array}$ \\
Psycho Pleasure & $\begin{array}{l}\text { The pleasure related to the cognitive demands and emotional response } \\
\text { engendered by using the product, such as useful, easy to use, and fun to use. }\end{array}$ \\
Socio Pleasure & $\begin{array}{l}\text { The pleasure derived from relationships with others or as an image may play a } \\
\text { role in society. }\end{array}$ \\
Ideo Pleasure & $\begin{array}{l}\text { The pleasure related to people's values, for example, the aesthetics of a product } \\
\text { and the values that a product embodies to make people feel better. }\end{array}$ \\
\hline
\end{tabular}

backgrounds to the two kinds of products and which factors can bring positive emotion.

\section{Materials and Methods}

Pleasure can be discussed in the same language used by those who have those experiences [26]. The subjective evaluation using a questionnaire-based checklist to be rated by participants is a commonly self-report method for measuring the effect of users' response to a product [27]. Jordan's four types of pleasure are used as tools to measure subjects' positive responses that the product can bring.

\subsection{Stimuli}

Ming' Design team conducted the stimuli consisting of four keyboards, and it was the fruit of the design project belonging to the DTIT program supported by Jensin International Technology Corp. In the era of human-computer interaction, people spend much time using keyboards, mice, or other input devices, providing them with an interface to interact with the computer. In the perceptive of usability, the keyboard should meet the needs of speedy, accurate, and comfortable information input. Two groups applied data collection, behavior observation, and ergonomics into usability design and then got the keyboard A and keyboard B, as shown in Figure 2 [28]. In the process of pleasure design, F1 racing elements symbolizing speed were integrated into the keyboard according to the design principle mentioned above. Beyond meeting the usability factors, keyboard F kept more details of car modeling, whereas keyboard L chose a concise shape to reflect the racing car's sense and taste, as shown in Figure 3 [28]. The same two groups designed the stimuli to facilitate subjects' evaluation for the single variable of usability and pleasure.

\subsection{Evaluation Checklists}

The options include in all four pleasure categories: physiological pleasure, psychological pleasure, sociological pleasure, and ideological pleasure [18]. Physiological pleasure is to do with pleasures derived from the multiple body sense organs, including connection with touch, taste, and smell, as well as feelings of sensuality. 
A

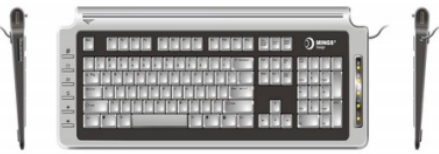

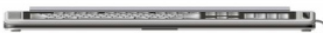

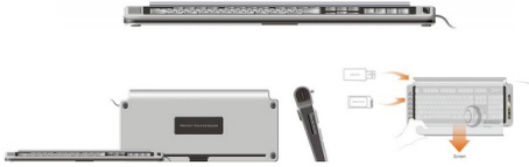

Figure 2. Usability keyboards design.

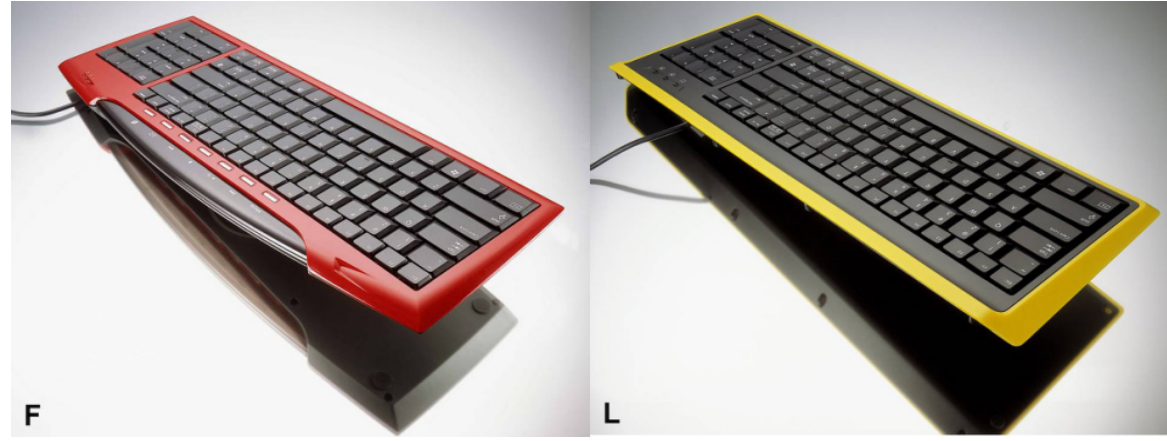

Figure 3. Pleasure keyboards design.

In the context of the keyboard, holding in hand, touching, and operating it may be the factors that affect how pleasurable it is for users. Psychological pleasure in the case of a product might include issues relating to the cognitive demands and emotional response engendered by using the product, such as useful, easy to use, and fun to use. Sociological pleasure is enjoyment derived from relationships with others or as an image that may play a role in society. The ideological pleasure pertains to people's values, such as the aesthetics of a product and the values that a product makes people feel better. According to the four types of pleasure analysis, the evaluation checklist was built to evaluate the potential reactions that a user may have to the keyboard design, as shown in Table 2.

\subsection{Participants}

A total of 343 university students ( 147 males and 196 females; males' age $=23.17$ \pm 5.69 ; females' age $=21.40 \pm 1.63$ ) who participated in the experiment came from various majors. The majority of participants came from design-related departments (162/47.2\%), followed by departments of business and management (80/23.3\%), departments of engineering (47/13.7\%), and others (54/15.8\%)

\subsection{Experimental Procedure}

According to the purpose of this study, the questionnaire was designed in three parts as Table 3. In the first part, there were basic personal data, including gender, age, major and educational background. The second part is ranking of the evaluation 
Table 2. The evaluation checklist for keyboards design test.

\begin{tabular}{l}
\multicolumn{1}{c}{ Evaluation Checklist/Variables } \\
\hline Physiological pleasure \\
1. The keyboard feels good in the hand. \\
2. The buttons feel good to the touch. \\
3. The keyboard can be comfortably operated. \\
Psychological pleasure \\
4. The keyboard has useful functions. \\
5. The keyboard is easy to use. \\
6. The keyboard is fun to use. \\
Sociological pleasure [19] and \\
7. I feel proud when others see me with the keyboard. \\
8. Owing and using the keyboard enhances my social image. \\
9. I enjoy being permanently comfortable by the keyboard. \\
Ideological pleasure \\
10. Having this keyboard makes me feel better about myself. \\
11. I find this keyboard to be aesthetically pleasing. \\
12. I feel the keyboard with a good taste.
\end{tabular}

Table 3. Structure of questionnaire.

\begin{tabular}{cc}
\hline Questionnaire Classification & Classification Item \\
\hline Part 1. Basic personal data & Gender/Age/Major/Educational background \\
Part 2. Pleasure evaluation & Physiological/Psychological/Sociological/Ideological (1 to 5 points) \\
Part 3. Preference & A or B/F or L/Four keyboards \\
\hline
\end{tabular}

checklist, consisting of four groups with three items in each group as the test standard for product evaluation through a Likert scale of 1 to 5 (1 being "strongly disagree", 5 being "strongly agree") As the third part, the preference for keyboard A or B, keyboard F or L, and the four keyboards was selected. The questionnaire was established on the website to collect data:

https://docs.google.com/forms/d/1EkYA1qZBxnQmg8XwKcOZVSFvTUzJ0kBA VtsmPN25p84/edit.

\subsection{Statistical Analysis}

Firstly, One-way ANOVA was conducted to test the difference in the perception of four pleasures. For programs reaching the significance level, we used post-hoc analysis to compare the averages (significance level was set at 0.05 ). Then, the ChiSquare test was performed to find out whether there was a significant difference in preference between usability and pleasure according to gender, age, major and educational background (significance level was set at 0.05).

\section{Results and Discussion}

\subsection{Perception Difference of Pleasure among Product Design}

The purpose of this study was to find out whether there are any differences in 
pleasure experience between usability-based products and pleasure-based products. Four types of pleasure were used as the independent variable, and the score of three items of each pleasure was taken as the dependent variable, and Oneway ANOVA was performed. From the analysis result in Table 4, the significance can be seen.

According to the evaluation results of each keyboard, there are significant differences in the four types of pleasure. Furthermore, post-hoc comparative analysis shows that physiological and psychological pleasures obtain higher scores than sociological and ideological pleasure. It was explained that the products should not provide all four types of pleasure, and the benefits associated with a particular product cover the different types of pleasure [19]. As the computer's input device, the keyboard's primary function is to enter text and data. While though the score of social pleasure and ideological pleasure are lower than the other two types, Table 5 shows that their perceptive effect in pleasure design ( $\mathrm{F}$ and $\mathrm{L}$ ) is obviously higher than usability design (A and $\mathrm{B}$ ). It indicates that design pleasure into the product would help obtain more social and ideological pleasure. In addition, the score of physiological pleasure in pleasure products ( $\mathrm{F}$ and $\mathrm{L}$ ) was higher than

Table 4. Results of one-way ANOVA.

\begin{tabular}{|c|c|c|c|c|c|}
\hline \multicolumn{6}{|l|}{ Keyboard-A } \\
\hline Source of variation & SS & $\mathrm{DF}$ & MS & F & Post-hoc \\
\hline Between Groups & 90.636 & 3 & 30.212 & & \\
\hline Within Groups & 4957.103 & 4099 & 1.209 & $24.982^{\star \star \star}$ & $\begin{array}{l}2>1>3 \\
2>1>4\end{array}$ \\
\hline Total & 5047.739 & 4102 & & & \\
\hline \multicolumn{6}{|l|}{ Keyboard-B } \\
\hline Source of variation & sS & $\mathrm{DF}$ & MS & F & Post-hoc \\
\hline Between Groups & 85.856 & 3 & 28.619 & & \\
\hline Within Groups & 4639.587 & 4101 & 1.131 & $25.297^{\star \star \star}$ & $\begin{array}{l}1>3,1>4, \\
2>3,2>4\end{array}$ \\
\hline Total & 4725.443 & 4104 & & & \\
\hline \multicolumn{6}{|l|}{ Keyboard-F } \\
\hline Source of variation & SS & $\mathrm{DF}$ & MS & F & Post-hoc \\
\hline Between Groups & 316.051 & 3 & 105.350 & & \\
\hline Within Groups & 5296.771 & 4103 & 1.291 & $102.484^{\star * \star}$ & $\begin{array}{l}1>3,1>4 \\
2>3,2>4\end{array}$ \\
\hline Total & 5612.822 & 4106 & & & \\
\hline \multicolumn{6}{|l|}{ Keyboard-L } \\
\hline Source of variation & SS & $\mathrm{DF}$ & MS & F & Post-hoc \\
\hline Between Groups & 163.969 & 3 & 54.656 & & \\
\hline Within Groups & 4599.659 & 4105 & 1.121 & $64.657^{\star * *}$ & $1>2>4>3$ \\
\hline Total & 4763.629 & 4108 & & & \\
\hline
\end{tabular}

${ }^{* *} \mathrm{P}<0.001 ; \mathrm{SS}=$ Sum of squares, DF $=$ Degrees of freedom, MS = Mean squares, $\mathrm{F}=$ Fratio. 1. Physiological pleasure; 2. Psychological pleasure; 3 . Sociological pleasure; 4 . Ideological pleasure. 
Table 5. Results of descriptive statistics.

\begin{tabular}{|c|c|c|c|c|c|c|c|c|c|}
\hline \multirow{2}{*}{ All Subjects } & \multirow{2}{*}{$\mathbf{N}$} & \multicolumn{2}{|c|}{ Keyboard A } & \multicolumn{2}{|c|}{ Keyboard B } & \multicolumn{2}{|c|}{ Keyboard F } & \multicolumn{2}{|c|}{ Keyboard L } \\
\hline & & mean & s.d. & mean & s.d. & mean & s.d. & mean & s.d. \\
\hline Phys. 1 & 343 & 2.97 & 1.01 & 3.08 & 0.99 & 3.28 & 1.00 & 3.57 & 0.92 \\
\hline Phys. 2 & 343 & 3.00 & 1.00 & 3.04 & 0.96 & 3.36 & 1.02 & 3.55 & 0.93 \\
\hline Phys. 3 & 343 & 2.99 & 1.03 & 3.07 & 0.98 & 3.26 & 1.03 & 3.54 & 0.95 \\
\hline Psyc. 4 & 343 & 3.31 & 1.04 & 3.22 & 1.04 & 3.42 & 0.97 & 3.52 & 0.95 \\
\hline Psyc. 5 & 343 & 3.02 & 1.13 & 3.08 & 1.03 & 3.56 & 1.02 & 3.66 & 0.93 \\
\hline Psyc. 6 & 343 & 2.98 & 1.14 & 2.97 & 1.06 & 2.98 & 1.14 & 3.16 & 1.01 \\
\hline Soci. 7 & 343 & 2.88 & 1.14 & 2.82 & 1.11 & 2.73 & 1.20 & 3.01 & 1.16 \\
\hline Soci. 8 & 343 & 2.66 & 1.10 & 2.70 & 1.11 & 2.60 & 1.23 & 2.95 & 1.15 \\
\hline Soci. 9 & 343 & 2.80 & 1.08 & 2.83 & 1.05 & 2.95 & 1.17 & 3.22 & 1.10 \\
\hline Ideo. 10 & 343 & 2.69 & 1.13 & 2.77 & 1.12 & 2.62 & 1.16 & 3.04 & 1.16 \\
\hline Ideo. 11 & 343 & 2.78 & 1.16 & 2.81 & 1.14 & 2.83 & 1.27 & 3.25 & 1.16 \\
\hline Ideo. 12 & 343 & 2.77 & 1.19 & 2.82 & 1.14 & 2.81 & 1.27 & 3.21 & 1.14 \\
\hline A or B-13 & 343 & & A: 38.3 & B: $61.7 \%$ & & & & & \\
\hline F or L-14 & 343 & & & & & & 39.1 & : $60.9 \%$ & \\
\hline Most-15 & 343 & & & A: 17.29 & : 18.6 & $\mathrm{~F}: 21.99^{\circ}$ & : 42.3\% & & \\
\hline
\end{tabular}

usability products ( $A$ and $B$ ), which is consistent with the claim that the beautiful product looks more work better [11].

\subsection{Difference Analysis of Preference According to Gender}

A Chi-Square test was applied to analyze the differences of preference according to gender, as results were shown in Table 6 . In the choice of $\mathrm{F}$ or L, or one of the four keyboards, there are significant differences in preference between males and females.

In the selection of keyboard $\mathrm{F}$ or $\mathrm{L}$, the proportion of males choosing keyboard $\mathrm{F}$ was significantly more than that of females, while the result for keyboard L was just the opposite. When picked the favorite product from the four options, more males and females turned to choose keyboard F and L, especially the keyboard L was preferred by more favor from women.

The results show that gender has a significant impact on the preference of pleasure design and usability design. Both males and females are more favorites of pleasure-based products, whereas features of their preference is different.

\subsection{Difference Analysis of Preference According to Age}

A Chi-Square test was used to explore the differences in the preference of the usability and the pleasure products by different groups of age, as shown in Table 7 . The results with significant differences were for all choice categories.

Both the groups 31 - 35 and above 50 years old selecting keyboard A from A 
Table 6. Analysis of differences in preference among gender groups.

\begin{tabular}{|c|c|c|c|c|c|c|c|c|c|}
\hline & Keyboards & & \multicolumn{2}{|c|}{ A } & \multicolumn{2}{|c|}{ B } & Total & Chi-Square & DF \\
\hline \multirow{6}{*}{ Gender } & \multirow{2}{*}{ Male } & $\mathrm{N}$ & \multicolumn{2}{|c|}{58} & \multicolumn{2}{|c|}{89} & 147 & \multirow{6}{*}{0.145} & \multirow{6}{*}{1} \\
\hline & & $\%$ & \multicolumn{2}{|c|}{$39.5 \%$} & \multicolumn{2}{|c|}{$60.5 \%$} & $100.0 \%$ & & \\
\hline & \multirow{2}{*}{ Female } & $\mathrm{N}$ & \multicolumn{2}{|c|}{73} & \multicolumn{2}{|c|}{122} & 196 & & \\
\hline & & $\%$ & & & & & $100.0 \%$ & & \\
\hline & \multirow{2}{*}{ Total } & $\mathrm{N}$ & \multicolumn{2}{|c|}{131} & \multicolumn{2}{|c|}{211} & 343 & & \\
\hline & & $\%$ & \multicolumn{2}{|c|}{$38.3 \%$} & \multicolumn{2}{|c|}{$61.7 \%$} & $100 \%$ & & \\
\hline & \multicolumn{2}{|l|}{ Keyboards } & \multicolumn{2}{|c|}{$\mathrm{F}$} & \multicolumn{2}{|c|}{$\mathrm{L}$} & Total & Chi-Square & DF \\
\hline \multirow{7}{*}{ Gender } & \multirow{2}{*}{ Male } & $\mathrm{N}$ & \multicolumn{2}{|c|}{68} & \multicolumn{2}{|c|}{79} & 147 & & \\
\hline & & $\%$ & \multicolumn{2}{|c|}{$46.3 \%$} & \multicolumn{2}{|c|}{$53.7 \%$} & $100.0 \%$ & & \\
\hline & \multirow{2}{*}{ Female } & $\mathrm{N}$ & \multicolumn{2}{|c|}{66} & \multicolumn{2}{|c|}{130} & 196 & $5-500 x$ & 1 \\
\hline & & $\%$ & \multicolumn{2}{|c|}{$33.7 \%$} & \multicolumn{2}{|c|}{$66.3 \%$} & $100.0 \%$ & & \\
\hline & \multirow{2}{*}{ Total } & $\mathrm{N}$ & \multicolumn{2}{|c|}{134} & & & 343 & & \\
\hline & & $\%$ & & & & & $100.0 \%$ & & \\
\hline & Keyboards & & A & B & $\mathrm{F}$ & $\mathrm{L}$ & Total & Chi-Square & DF \\
\hline & & $\mathrm{N}$ & 24 & 35 & 39 & 49 & 147 & & \\
\hline & & $\%$ & $16.2 \%$ & $23.8 \%$ & $26.6 \%$ & $33.4 \%$ & $100.0 \%$ & & \\
\hline$C$ & $F_{e}$ & $\mathrm{~N}$ & 35 & 29 & 36 & 96 & 196 & 1) 100 & \\
\hline Gender & Termare & $\%$ & $17.8 \%$ & $14.8 \%$ & $18.4 \%$ & $49.0 \%$ & $100.0 \%$ & 11.170 & 1 \\
\hline & T & $\mathrm{N}$ & 59 & 64 & 75 & 145 & 343 & & \\
\hline & Forat & $\%$ & $17.2 \%$ & $18.6 \%$ & $21.9 \%$ & $42.3 \%$ & $100.0 \%$ & & \\
\hline
\end{tabular}

${ }^{*} \mathrm{P}<0.05 ; \mathrm{DF}=$ Degrees of freedom.

Table 7. Analysis of differences in preference among age groups.

\begin{tabular}{|c|c|c|c|c|c|c|c|}
\hline & Keyboards & & A & B & Total & Chi-Square & $\mathrm{DF}$ \\
\hline \multirow{8}{*}{ Age } & \multirow{2}{*}{ Under 30} & $\mathrm{~N}$ & 67 & 139 & 206 & \multirow{8}{*}{$7.704^{*}$} & \multirow{8}{*}{2} \\
\hline & & $\%$ & $32.5 \%$ & $67.5 \%$ & $100.0 \%$ & & \\
\hline & \multirow{2}{*}{$31-50$} & $\mathrm{~N}$ & 46 & 55 & 101 & & \\
\hline & & $\%$ & $45.5 \%$ & $54.5 \%$ & $100.0 \%$ & & \\
\hline & \multirow{2}{*}{ Above 50} & $\mathrm{~N}$ & 18 & 17 & 35 & & \\
\hline & & $\%$ & $51.4 \%$ & $48.6 \%$ & $100 \&$ & & \\
\hline & \multirow{2}{*}{ Total } & $\mathrm{N}$ & 131 & 211 & 343 & & \\
\hline & & $\%$ & $38.3 \%$ & $61.7 \%$ & $100.0 \%$ & & \\
\hline & Keyboards & & $\mathrm{F}$ & $\mathrm{L}$ & Total & Chi-Square & DF \\
\hline \multirow{8}{*}{ Age } & \multirow{2}{*}{ Under 30} & $\mathrm{~N}$ & 66 & 140 & 206 & \multirow{8}{*}{$12.254^{\star \star}$} & \multirow{8}{*}{2} \\
\hline & & $\%$ & $32.0 \%$ & $68.0 \%$ & $100.0 \%$ & & \\
\hline & & $\mathrm{N}$ & 47 & 54 & 101 & & \\
\hline & 31 & $\%$ & $46.5 \%$ & $53.5 \%$ & $100.0 \%$ & & \\
\hline & \multirow{2}{*}{ Above 50} & $\mathrm{~N}$ & 21 & 15 & 36 & & \\
\hline & & $\%$ & $58.3 \%$ & $41.7 \%$ & $100.0 \%$ & & \\
\hline & \multirow{2}{*}{ Total } & $\mathrm{N}$ & 134 & 209 & 343 & & \\
\hline & & $\%$ & $39.1 \%$ & $60.9 \%$ & $100.0 \%$ & & \\
\hline
\end{tabular}




\section{Continued}

\begin{tabular}{|c|c|c|c|c|c|c|c|c|c|}
\hline & Keyboards & & A & B & $\mathrm{F}$ & $\mathrm{L}$ & Total & Chi-Square & DF \\
\hline \multirow{8}{*}{ Age } & T 1 & $\mathrm{~N}$ & 23 & 34 & 44 & 105 & 206 & \multirow{8}{*}{$24.645^{\star \star \star}$} & \\
\hline & & $\%$ & $11.2 \%$ & $16.5 \%$ & $21.4 \%$ & $50.9 \%$ & $100.0 \%$ & & \\
\hline & \multirow{2}{*}{$31-50$} & $\mathrm{~N}$ & 27 & 25 & 20 & 29 & 101 & & \\
\hline & & $\%$ & $26.7 \%$ & $24.8 \%$ & $19.8 \%$ & $28.7 \%$ & $100.0 \%$ & & \\
\hline & \multirow{2}{*}{ Above 50} & $\mathrm{~N}$ & 9 & 5 & 11 & 11 & 36 & & 2 \\
\hline & & $\%$ & $25.0 \%$ & $13.8 \%$ & $30.6 \%$ & $30.6 \%$ & $100.0 \%$ & & \\
\hline & \multirow{2}{*}{ Total } & $\mathrm{N}$ & 59 & 64 & 75 & 145 & 343 & & \\
\hline & & $\%$ & $17.2 \%$ & $18.6 \%$ & $21.9 \%$ & $42.3 \%$ & $100.0 \%$ & & \\
\hline
\end{tabular}

${ }^{*} \mathrm{P}<0.05^{* * \mathrm{P}}<0.01^{* * * \mathrm{P}}<0.001 ; \mathrm{DF}=$ Degrees of freedom.

and $\mathrm{B}$ is significantly higher than the average proportion, while the result from $\mathrm{F}$ and $\mathrm{L}$ is keyboard F. However, the group under 30 years old has opposite preferences. When in the face of the four options, more subjects chose pleasure-based products, especially keyboard L. Meanwhile, young people under 30 still show a significant preference for keyboard $\mathrm{L}$ above average.

Generally, different age groups have more preference for pleasure than usability design. In particular, young people have a stronger need for "pleasure" for the user experience. Besides, there are differences in preferences between the young and elderly subjects.

\subsection{Difference Analysis of Preference According to Major}

A Chi-Square test was conducted to analyze the differences of preference according to major. Table 8 shows that the four groups of people with different majors have significant differences in the selection of keyboards $\mathrm{F}$ or L $\left(\chi^{2}=12.284, \mathrm{P}<\right.$ $0.01)$, and four options $\left(\chi^{2}=34.547, \mathrm{P}<0.001\right)$. In the choice of $\mathrm{F}$ or $\mathrm{L}$, participants with engineering backgrounds show a higher proportion of preference for keyboard $\mathrm{F}$ than average, while more people with art and design backgrounds are favored keyboard L. From the result of one out of four, the subjects with engineering backgrounds prefer usability design (A and B) above average, while other groups are favorite of pleasure design (F and L). Significantly, the preference of art design majors for keyboard $\mathrm{L}$ is obviously higher than the average.

The subjects with the most majors pay more attention to pleasure than usability, whereas particular majors such as engineering show the opposite choice. It indicates that there are significant differences between engineering and other majors in terms of perceived preference. (Table 8)

\subsection{Difference Analysis of Preference According to Educational Background}

A Chi-Square test was made to analyze the differences of preference among subjects with different educational backgrounds, as shown in Table 9. There are sig- 
nificant differences in the choice of keyboard A or B $\left(\chi^{2}=8.371, \mathrm{P}<0.01\right)$ between undergraduate and postgraduate, as the former group shows an obvious

Table 8. Analysis of differences in preference among majors.

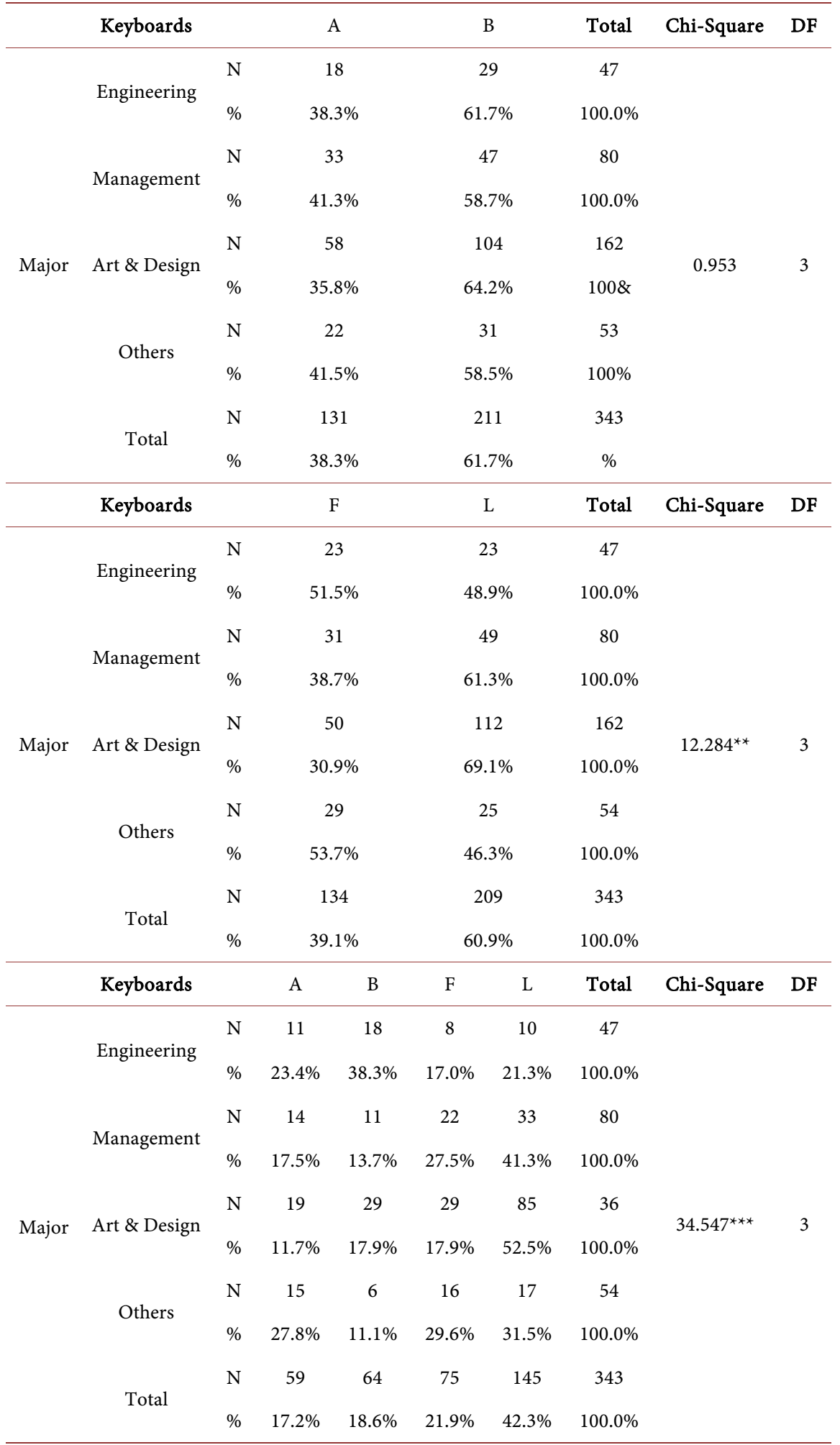

${ }^{* *} \mathrm{P}<0.01{ }^{* * *} \mathrm{P}<0.001 ; \mathrm{DF}=$ Degrees of freedom. 
Table 9. Analysis of differences in preference in educational context.

\begin{tabular}{|c|c|c|c|c|c|c|c|c|c|}
\hline & \multicolumn{2}{|l|}{ Keyboards } & \multicolumn{2}{|c|}{ A } & \multicolumn{2}{|c|}{ B } & Total & Chi-Square & $\mathrm{DF}$ \\
\hline \multirow{7}{*}{ Education } & \multirow{2}{*}{$\begin{array}{l}\text { Under } \\
\text { Graduate }\end{array}$} & $\mathrm{N}$ & \multicolumn{2}{|c|}{63} & \multicolumn{2}{|c|}{135} & 198 & \multirow{6}{*}{$8.371^{* *}$} & \multirow{6}{*}{1} \\
\hline & & $\%$ & \multicolumn{2}{|c|}{$31.8 \%$} & \multicolumn{2}{|c|}{$68.2 \%$} & $100.0 \%$ & & \\
\hline & Post & $\mathrm{N}$ & \multicolumn{2}{|c|}{68} & \multicolumn{2}{|c|}{76} & 144 & & \\
\hline & Graduate & $\%$ & \multicolumn{2}{|c|}{$47.2 \%$} & \multicolumn{2}{|c|}{$52.8 \%$} & $100.0 \%$ & & \\
\hline & \multirow{2}{*}{ Total } & $\mathrm{N}$ & \multicolumn{2}{|c|}{131} & \multicolumn{2}{|c|}{211} & 343 & & \\
\hline & & $\%$ & \multicolumn{2}{|c|}{$38.3 \%$} & \multicolumn{2}{|c|}{$61.7 \%$} & $100 \%$ & & \\
\hline & \multicolumn{2}{|l|}{ Keyboards } & \multicolumn{2}{|c|}{$\mathrm{F}$} & \multicolumn{2}{|c|}{$\mathrm{L}$} & Total & Chi-Square & DF \\
\hline \multirow{7}{*}{ Education } & Under & $\mathrm{N}$ & \multicolumn{2}{|c|}{71} & \multicolumn{2}{|c|}{128} & 199 & & \\
\hline & Graduate & $\%$ & \multicolumn{2}{|c|}{$35.7 \%$} & \multicolumn{2}{|c|}{$64.3 \%$} & $100.0 \%$ & & \\
\hline & Post & $\mathrm{N}$ & \multicolumn{2}{|c|}{63} & \multicolumn{2}{|c|}{81} & 144 & 278 & 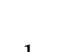 \\
\hline & Graduate & $\%$ & \multicolumn{2}{|c|}{$43.7 \%$} & \multicolumn{2}{|c|}{$56.3 \%$} & $100.0 \%$ & 2.287 & 1 \\
\hline & & $\mathrm{N}$ & \multicolumn{2}{|c|}{134} & & & 343 & & \\
\hline & Total & $\%$ & & & & & $100.0 \%$ & & \\
\hline & Keyboards & & A & B & $\mathrm{F}$ & $\mathrm{L}$ & Total & Chi-Square & DF \\
\hline & Under & $\mathrm{N}$ & 29 & 33 & 43 & 94 & 199 & & \\
\hline & Graduate & $\%$ & $14.6 \%$ & $16.6 \%$ & $21.6 \%$ & $47.2 \%$ & $100.0 \%$ & & \\
\hline & Post & $\mathrm{N}$ & 30 & 31 & 32 & 51 & 144 & & \\
\hline Education & Graduate & $\%$ & $20.9 \%$ & $21.5 \%$ & $22.2 \%$ & $35.4 \%$ & $100.0 \%$ & 5.774 & 1 \\
\hline & Total & $\mathrm{N}$ & 59 & 64 & 75 & 145 & 343 & & \\
\hline & Iotar & $\%$ & $17.2 \%$ & $18.6 \%$ & $21.9 \%$ & $42.3 \%$ & $100.0 \%$ & & \\
\hline
\end{tabular}

${ }^{*} \mathrm{P}<0.01 ; \mathrm{DF}=$ Degrees of freedom.

preference for keyboard B. However, when faced with four options, both the groups of undergraduate and postgraduate still turned to choose the pleasure design, especially keyboard $\mathrm{L}$.

The results indicate that subjects with different educational backgrounds similar prefer pleasure design to usability design. Though the education factor only shows the significant difference in the preference of usability products, there are a higher proportion of undergraduates who prefer keyboard $\mathrm{L}$.

\section{Conclusions}

The pleasure design can get higher physiological pleasure, which means that the attractive product looks more work better. Therefore, by considering pleasure elements in the design process, users can feel that the product would be used more comfortably and effectively. Secondly, in terms of gender, age, major and educational background, most participants prefer pleasure design to usability design. According to the results, there are differences in preference for pleasure between the young and the older people. Unlike most majors who prefer pleasure products, people with engineering backgrounds are favored usability products. Be- 
sides, there are also differences in preference for pleasure design between art design and both management and others. As the most preferred sample, keyboard $\mathrm{L}$ is obviously preferred by more subjects, especially youth undergraduates with art and design backgrounds. Compared with keyboard F, keyboard L refined elements of the $\mathrm{F} 1$ racing car more concisely to avoid affecting the feel of touch and operate. Even though image browsing, a good sense of use and pleasure can still be conveyed in different dimensions. Its more design attributes are worth to be further explored.

Product development is no longer only about implementing features and testing their usability, but also about designing products that are enjoyable and support fundamental human needs and values. These results demonstrate the need of people for a pleasant experience. Furthermore, the users' characteristics and preferences should be considered during design pleasure into the product. The construction of this study is to provide designers with a valuable reference for examining the way how to design "pleasure" into product and the interactive experience of users in the design process.

\section{Acknowledgements}

The authors wish to thank Mings' Design Team for joining the DTIT program at NTUA and designing the keyboards for this study.

\section{Conflicts of Interest}

The authors declare no conflicts of interest regarding the publication of this paper.

\section{References}

[1] Straker, K. and Wrigley, C. (2015) The Role of Emotion in Product, Service and Business Model Design. Journal of Entrepreneurship, Management and Innovation, 11 11-28. https://doi.org/10.7341/20151112

[2] Ekkekakis, P. and Zenko, Z. (2016) Measurement of Affective Responses to Exercise: From "Affectless Arousal" to "The Most Well-Characterized" Relationship between the Body and Affect. In: Meiselman, H.L., Ed., Emotion Measurement, Woodhead Publishing, Cambridge, 299-301. https://doi.org/10.1016/B978-0-08-100508-8.00012-6

[3] Aftab, M. and Rusli, H.A. (2017) Designing Visceral, Behavioural and Reflective Products. Chinese Journal of Mechanical Engineering, 30, 1058-1068. https://doi.org/10.1007/s10033-017-0161-x

[4] Van Gorp, T. and Adams, E. (2012) Design for Emotion. Elsevier, Amsterdam, 9-10. https://doi.org/10.1016/B978-0-12-386531-1.00001-6

[5] Lottridge, D., et al. (2011) Affective Interaction: Understanding, Evaluating, and Designing for Human Emotion. Reviews of Human Factors and Ergonomics, 7, 197-217. https://doi.org/10.1177/1557234X11410385

[6] Desmet, P.M.A. (2012) Faces of Product Pleasure: 25 Positive Emotions in HumanProduct Interactions. International Journal of Design, 6, 1-29.

[7] Zhao, T. and Zhu, T. (2019) Exploration of Product Design Emotion Based on Three- 
Level Theory of Emotional Design. International Conference on Human Interaction and Emerging Technologies, Lausanne, 23-25 April 2019, 169-175. https://doi.org/10.1007/978-3-030-25629-6 27

[8] Hekkert, P. (2006) Design Aesthetics: Principles of Pleasure in Design. Psychology Science, 48, 157-172.

[9] Blijlevens, J., et al. (2017) The Aesthetic Pleasure in Design Scale: The Development of a Scale to Measure Aesthetic Pleasure for Designed Artifacts. Psychology of Aesthetics, Creativity, and the Arts, 11, 86-98. https://doi.org/10.1037/aca0000098

[10] Triberti, S., et al. (2017) Developing Emotional Design: Emotions as Cognitive Processes and Their Role in the Design of Interactive Technologies. Frontiers in Psychology, 8 , 1773. https://doi.org/10.3389/fpsyg.2017.01773

[11] Norman, D. (2005) Emotional Design: Why We Love (or Hate) Everyday Things. Basic Books, New York, 17-24.

[12] Desmet, P.M., et al. (2007) Emotional Design; Application of a Research-Based Design Approach. Knowledge, Technology \& Policy, 20, 141-155.

https://doi.org/10.1007/s12130-007-9018-4

[13] Hancock, P.A., et al. (2005) Hedonomics: The Power of Positive and Pleasurable Ergonomics. Ergonomics in Design, 13, 8-14. https://doi.org/10.1177/106480460501300104

[14] Hassenzahl, M. and Tractinsky, N. (2006) User Experience-A Research Agenda. Behaviour \& Information Technology, 25, 91-97. https://doi.org/10.1080/01449290500330331

[15] Jeon, M. (2017) Emotions and Affect in Human Factors and Human-Computer Interaction: Taxonomy, Theories, Approaches, and Methods. In: Emotions and Affect in Human Factors and Human-Computer Interaction, Academic Press, Cambridge, 3-26. https://doi.org/10.1016/B978-0-12-801851-4.00001-X

[16] Desmet, P. and Hekkert, P. (2007) Framework of Product Experience. International Journal of Design, 1, 57-66.

[17] Han, F. and Bowerman, J. (2015) Product Pleasure: A Tale of Two Cultures. International Journal of Humanities and Social Science Invention, 4, 69-74.

[18] Tiger, L. (1992) The Pursuit of Pleasure. Little, Brown \& Company, Kansas.

[19] Jordan, P.W. (2000) Designing Pleasurable Products: An Introduction to the New Human Factors. Taylor and Francis, London, 10-50.

[20] Schifferstein, H.N.J., et al. (2004) Designing Consumer-Product Attachment. In: Mcdonagh, D., et al., Eds., Design and Emotion: The Experience of Everyday Things, Taylor \& Francis, London, 327-311. https://doi.org/10.1201/9780203608173-c59

[21] Creusen, M.E.H. and Schoormans, J.P.L. (2010) The Different Roles of Product Appearance in Consumer Choice. Journal of Product Innovation Management, 22, 63-81. https://doi.org/10.1111/j.0737-6782.2005.00103.x

[22] Van Kuijk, J., Daalhuizen, J. and Christiaans, H. (2019) Drivers of Usability in Product Design Practice: Induction of a Framework through a Case Study of Three Product Development Projects. Design Studies, 60, 139-179. https://doi.org/10.1016/j.destud.2018.06.002

[23] Seva, R.R., et al. (2011) Product Design Enhancement Using Apparent Usability and Affective Quality. Applied Ergonomics, 42, 511-517.

https://doi.org/10.1016/j.apergo.2010.09.009

[24] Jordan, P.W. (1998) Human Factors for Pleasure in Product Use. Applied Ergonom- 
ics, 29, 25-33. https://doi.org/10.1016/S0003-6870(97)00022-7

[25] Jordan, P.W. (1997) Putting the Pleasure into Products. IEE Review, 43, 249-252. https://doi.org/10.1049/ir:19970608

[26] Brown, B. and Juhlin, O. (2018) What Is Pleasure? In: Blythe, M. and Monk, A., Eds., Funology 2: From Usability to Enjoyment, Kluwer, Dordrecht, 47-59. https://doi.org/10.1007/978-3-319-68213-6 4

[27] Ma, J.-P., et al. (2013) Affective Fusion of PAD Model-Based Tactile Sense: A Case Study of Teacups. International Conference on Cross-Cultural Design, Las Vegas, 21-26 July 2013, 420-429. https://doi.org/10.1007/978-3-642-39143-9 47

[28] Kreifeldt, J., et al. (2018) S.A.D in Education and CHEER in Practice: A Case Study of DTIT Program at NTUA. International Conference on Cross-Cultural Design, Las Vegas, 15-20 July 2018, 160-171. https://doi.org/10.1007/978-3-319-92252-2 12 